\title{
Teoria do Direito da Recuperação e Insolvência Transfronteiriças: afastando-se do tradicional debate entre universalismo e territorialismo ${ }^{1}$
}

\author{
Cross-border insolvency and rescue law theory: moving away \\ from the traditional debate on universalism and territorialism
}

Emilie Ghio $^{2}$

\begin{abstract}
RESUMO
O marco teórico no qual a recuperação e a insolvência transfronteiriças são concebidas centrase na divisão entre universalismo e territorialismo, originada na academia americana. $\mathrm{O}$ presente artigo argumenta que esse marco não é o mais apropriado para a União Europeia no presente e deve ser substituído por outro.
\end{abstract}

\section{PALAVRAS CHAVE:}

Conflito de leis; recuperação corporativa; insolvência transfronteiriça; Direito da União Europeia; leis modelo.

\section{ABSTRACT}

The framework in which cross-border insolvency and rescue law is construed focuses on the universalism and territorialism divide, which originated in academic scholarship in the US. This article argues that this framework is not the most appropriate for the EU at present and should be replaced by another.

\section{KEYWORDS:}

Conflict of laws; Corporate recovery; Cross-border insolvency; EU law; Model laws.

\section{INTRODUÇÃO}

Emilie Ghio

emilie.ghio@bcu.ac.uk

1 A versão em inglês foi originariamente publicada na Revista International Company and Commercial Law Review (GHIO, Emilie. Cross-border insolvency and rescue law theory: moving away from the traditional debate on universalism and territorialism. International Company and Commercial Law Review, v. 29, n.12, p. 713-728 1 dez. 2018).

Tradução realizada por Paula Ladeira Vidal, aluna da Faculdade de Direito da Universidade Federal Fluminense e estagiária do Tribunal Regional Federal da $2^{\mathrm{a}}$ Região. Revisão da tradução por Ricardo Perlingeiro, Professor da Universidade Federal Fluminense e da Universidade Estácio de Sá e Desembargador Federal do Tribunal Regional Federal da $2^{\text {a }}$ Região.

${ }^{2}$ Lecturer in Law na Birmingham City University (Reino Unido). Doutora em Direito pela University College Cork (Irlanda). 
O tradicional marco teórico no qual a recuperação e a insolvência transfronteiriças são debatidas baseia-se na divisão entre universalismo e territorialismo. Contudo, nenhuma das abordagens tem sido adotada na prática ou por instrumentos normativos internacionais, e as instituições da União Europeia raramente têm se comprometido com tais conceitos. Sendo assim, o presente artigo defende que o debate em torno do universalismo e do territorialismo é latente e ultrapassado. De início, o trabalho procede a uma revisão do marco teórico clássico, com foco nas referidas noções. Em seguida, estuda a implementação do debate na prática, através da análise de dois instrumentos normativos internacionais: o Regulamento Europeu de Insolvência de $2000^{3}$ e a Lei Modelo de Insolvência Transfronteiriça de 1997 (Model Law on Cross-Border Insolvency Law 1997) da Comissão das Nações Unidas para o Direito do Comércio Internacional (United Nations Comission on International Trade Law - doravante, UNCITRAL). Por fim, determina que as abordagens idealistas conhecidas até o momento devem ser abandonadas e que é hora de renovar o debate e repensar a insolvência transfronteiriça e a teoria da recuperação judicial.

\section{POR QUE PRECISAMOS SUBSTITUIR O QUADRO TEÓRICO TRADICIONAL?}

A presente seção introduz o tradicional debate no qual o Direito da Insolvência Transfronteiriça é concebido. Ao fazê-lo, primeiramente revisa e estabelece relações com a literatura sobre os modelos regulatórios tradicionais, nomeadamente o universalismo e o territorialismo. ${ }^{4}$ Depois, passa do nível teórico para o estudo de duas importantes ferramentas no campo da insolvência e recuperação de empresas: o Regulamento Europeu de Insolvência

\footnotetext{
${ }^{3}$ UNIÃO EUROPEIA. Regulamento (CE) no 1346/2000 do Conselho, de 29 de maio de 2000. Relativo aos processos de insolvência. Jornal Oficial da União Europeia, $n^{\circ}$ L 160, [Bruxelas], 30 jun. 2000. p. 1-18. Essa normativa foi revogada e substituída pelo Regulamento (UE) 2015/848 do Parlamento Europeu e do Conselho, de 20 de maio de 2015. Jornal Oficial da União Europeia, nº L 141, [Bruxelas], 5 jun. 2015. p. 19-72.

${ }^{4}$ A autora tem consciência de que outros modelos foram desenvolvidos, como o contratualismo e a territorialidade cooperativa; contudo, o presente artigo foca nos dois extremos do espectro regulatório.
} 
de 2000 e a Lei Modelo de Insolvência Transfronteiriça de 1997 da UNCITRAL, com vistas a determinar como eles implementam os modelos teóricos na prática.

Ao longo das duas últimas décadas, acadêmicos têm vigorosamente debatido qual abordagem da insolvência transfronteiriça é a melhor. O debate geralmente centra-se em questões de previsibilidade, certeza, soberania nacional, justiça e eficiência. Nesse discurso teórico sobre o desenho mais apropriado para um sistema internacional de insolvência, duas abordagens têm sido tradicionalmente identificadas: o universalismo e o territorialismo. Apesar de amplamente aceito na literatura acadêmica que aquele é preferível a este, o cenário internacional é bem diferente. As divergências substanciais entre as legislações nacionais têm impedido o desenvolvimento de uma abordagem uniforme da insolvência multinacional:

\begin{abstract}
A consequente diversidade [da legislação de insolvência] tem sido extraordinariamente intensa, mesmo ante os padrões do Direito Internacional Privado, com o resultado de que a busca por princípios unificadores tem se mostrado, até o momento, inatingível. ${ }^{5}$
\end{abstract}

Com efeito, se, de um lado, o universalismo tem sido defendido como a solução ideal para a questão das insolvências transfronteiriças, de outro, é aceito por ora que ele é um objetivo inalcançável no futuro próximo. Acontecimentos internacionais recentes mostram que o universalismo tem sido largamente descartado e substituído por uma abordagem mais razoável e fundamentada, na tentativa de se alcançar soluções que, embora mais modestas que o objetivo inicial do universalismo, são mais facilmente concretizáveis.

\title{
2.1 Universalismo
}

O universalismo em sua forma mais pura promove um mundo ideal em que cada ordenamento jurídico e seus tribunais são obrigados a executar as ordens do tribunal que aprecia o caso. É por isso que "os defensores do universalismo não advogam a forma pura do modelo, em razão do reconhecimento prático das diferenças duradouras entre os sistemas políticos e econômicos, os regimes jurídicos e os sistemas judiciais". 6

\footnotetext{
${ }^{5}$ FLETCHER, Ian. Insolvency in private international Law. Oxford: Clarendon Press, 1999. p.10 (tradução nossa). 6 ADAMS, Edward; FINCKE, Jason. Coordinating cross-border bankruptcy: How territorialism saves universalism. Columbia Journal of European Law, v. 15, n. 1, p. 48, 2008 -2009 (tradução nossa). Ver também WESTBROOK, Jay. Universal Priorities. Texas International Law Journal, v. 33, n. 1, p. 28, 1998.
} 
De fato, o universalismo puro é um modelo confinado ao domínio teórico, pois exigiria que os Estados abdicassem de sua soberania. Eles concordariam ex ante que apenas uma jurisdição lidaria com o processo de insolvência e que todos os outros tribunais nacionais auxiliariam na coleta dos ativos. Desse modo, a forma de universalismo mais defendida "referese a [...] sistema em que um tribunal único, aquele do país de origem do devedor, tem competência sobre os bens do devedor, onde quer que estejam localizados no mundo, e os distribui de acordo com a lei desse mesmo país".

Em suma, "a defesa do universalismo baseia-se em razões de eficiência: regras claras diminuem os custos dos empréstimos e não distorcem as escolhas de investimento, assim como um único fórum proporciona uma série de economias administrativas". ${ }^{8}$

O professor Jay Westbrook é o mais ardente defensor de um modelo universal para a insolvência transfronteiriça, que ele simplesmente descreve como "a administração de insolvências multinacionais por um tribunal líder aplicando uma única lei falimentar". 9 Em geral, a literatura sobre os benefícios do universalismo prolifera e seus defensores usualmente apresentam o modelo como a "terra prometida", ${ }^{10}$ afirmando que outras abordagens resultam em uma maneira caótica de gerenciar os casos transfronteiriços, além de que um sistema único de tribunais especializados em insolvência pode "alcançar muitos dos benefícios proporcionados internamente por uma única lei falimentar nacional". ${ }^{11}$ Esses benefícios são: (1) aumento da previsibilidade jurídica ex ante; (2) facilitação dos casos de reestruturação; (3) diminuição de custos; (4) aumento do valor global dos ativos; e (5) incremento na isonomia e na justiça para todas as partes interessadas. ${ }^{12}$

Todavia, embora os argumentos a favor do estabelecimento de uma abordagem universal dos casos de insolvência e recuperação transfronteiriças sejam convincentes, a

\footnotetext{
7 ADAMS e FINCKE, op. cit.

${ }^{8}$ RASMUSSEN, Robert. A new approach to transnational insolvencies. Michigan Journal of International Law, v. 19, n. 1, p. 27, 1997 (tradução nossa).

${ }^{9}$ WESTBROOK, Jay. A global solution to multinational default. Michigan Law Review, v. 98, n. 7, p. 2277,2000 (tradução nossa).

10 POTTOW, John. Procedural incrementalism: A model for international bankruptcy. Virginia Journal of International Law, v. 45, n. 4, p. 947, 2005 (tradução nossa).

${ }^{11}$ WESTBROOK, op. cit., p. 2277.

12 Ver, em geral, WESTBROOK, Jay. Theory and pragmatism in global insolvencies: Choice of law and choice of forum. American Bankruptcy Law Journal, v. 65, n. 4, p. 457, 1991; Universal participation in transnational bankruptcies. In: CRANSTON, Ross (Ed.), Making Commercial Law: Essays in Honour of Roy Goode. Oxford: Clarendon Press, 1997. p. 419-438.
} 
maioria dos Estados continua relutante em abraçar esse modelo. Sua relutância normalmente se concentra em questões de: (1) soberania nacional; (2) um possível viés no sistema; e (3) a incerteza na definição do país de origem.

A primeira questão atrelada ao universalismo é que ele "ataca o âmago das profundas diferenças culturais e códigos legais fundados em princípios bastante distintos". ${ }^{13}$ Geralmente, os Estados são relutantes em deixar as leis de outros países afetarem sua própria soberania regulatória. Isso é especialmente verdade em campos politicamente sensíveis, como o Direito Falimentar, descrito como “"meta-direito', [perpassando] contrato, propriedade, e outros direitos que existem fora da falência". ${ }^{14}$

Em um de seus famosos artigos, o professor LoPucki - o principal detrator do universalismo - desenvolveu o exemplo Daimler Chrysler para demonstrar como diferentes direitos nacionais seriam prejudicados em um regime universalista. ${ }^{15} \mathrm{Em}$ seu cenário hipotético, a empresa Daimler Chrysler solicita proteção sob a lei de insolvência alemã, de modo que, numa perspectiva universalista, seus empregados devem apresentar reclamação ao tribunal alemão para reivindicar seus salários e benefícios. Portanto, o caso desses empregados seria resolvido conforme a lei alemã, e não a lei dos Estados Unidos (onde vinham prestando seus serviços). Esse cenário está em contradição direta com o argumento de Westbrook, no sentido de que, em um modelo universal, os benefícios de tal abordagem compensam qualquer desvantagem sofrida pelos empregados, que não estariam familiarizados com a legislação de insolvência estrangeira. Isso poderia lhes resultar em custos adicionais, a fim de se informarem sobre a lei em vigor em outras jurisdições.

Ademais, o professor Frederick Tung levantou um contra-argumento à alegação de justiça de Westbrook, afirmando que ela "pode favorecer sistematicamente alguns Estados e seus credores em detrimento de outros, tornando o universalismo pouco atraente para os desfavorecidos". ${ }^{16}$ De fato, no modelo universalista, o processo de insolvência é concentrado

\footnotetext{
${ }^{13}$ BOSHKOFF, Douglass. Some gloomy thoughts concerning cross-border insolvencies. Washington University Law Review, v. 72, n. 3, p. 936, 1994 (tradução nossa).

${ }^{14}$ TUNG, Frederick. Is international bankruptcy possible? Michigan Journal of International Law, v. 23, n. 1, p. 47, 2001 (apud BALZ, Manfred. The European Union Convention on insolvency proceedings. american bankruptcy law journal, v. 70, p. 486, 1996) (tradução nossa).

${ }^{15}$ LOPUCKI, Lynn. The case for cooperative territoriality. Michigan Law Review, v. 98, n. 7, p. 2223, 2000.

16 TUNG, Frederick. Fear of commitment in international bankruptcy. George Washington International Law Review, v. 33, p. 576, 2001 (tradução nossa).
} 
no centro de interesses principais do devedor ou em seu país de origem. Ocorre que para a maioria das multinacionais, o país de origem será um país desenvolvido, resultando na regência dos processos de insolvência pelas leis de Estados desenvolvidos, mesmo aqueles que lidem com países menos desenvolvidos. ${ }^{17}$ Isso também significa que os credores de outros países, que não o de origem, deverão se informar sobre a lei estrangeira aplicável aos seus casos. Se tais credores estiverem localizados em países menos desenvolvidos, pode haver um risco de que sejam "menos sofisticados que os seus pares industriais. Eles são menos capazes de se ajustar adequadamente $[. .$.$] aos riscos de vários regimes de insolvência estrangeiros". { }^{18}$

No mais, isso pode levar à propagação de paraísos internacionais de insolvência, que atraiam devedores em vésperas de bancarrota em busca de leis favoráveis. ${ }^{19}$ Consequentemente, tem se argumentado que o universalismo contribui para as desigualdades entres os países, já que alguns seriam mais "pesados em ativos" e "seriam rotineiramente superavitários [e, por conseguinte] não estariam interessados em aderir a um esquema internacional", ${ }^{20}$

Por fim, embora se argumente que o universalismo resulta em uma maior previsibilidade ex ante, alguns comentaristas discordam dessa visão e criticam a incerteza em torno da determinação do país de origem de uma empresa. Nos Estados Unidos, por exemplo, o universalismo vem sendo criticado pelos tribunais por ser impraticável:

$\mathrm{Na}$ era das corporações multinacionais, é possível que dois ou mais países possam ser considerados como o "país de origem" do devedor. Certamente, não se poderia empregar apenas a nação de incorporação [...] é preciso olhar para esse fator e [...] fatores como [...] [a localização do] "centro nervoso" do devedor, ativos, e credores $[\ldots]$ e onde o negócio do devedor é primariamente conduzido. ${ }^{21}$

A consequência é que os credores e os tribunais podem discordar sobre qual é o país de origem de um grupo corporativo. Acadêmicos que escrevem sobre o tema ainda não resolveram essa questão e os critérios de determinação permanecem abertos à discussão. Logo, em alguns

\footnotetext{
${ }^{17}$ Ibid., p. 577.

${ }^{18}$ Ibid., p. 577.

${ }^{19}$ Ibid., nota de rodapé 85 . Ver também GUZMAN, Andrew. International bankruptcy: In defense of universalism. Michigan Law Review, v. 98, n. 7, p. 2190, 2000.

${ }^{20}$ Ibid., p. 577. Ver também WESTBROOK, Jay. Theory and pragmatism in global insolvencies: Choice of law and choice of forum. American Bankruptcy Law Journal, v. 65, n. 4, p. 457, 1991.

${ }^{21}$ UNITED STATES BANKRUPTCY COURT, S.D. NEW YORK. Barclays Bank v. Maxwell Communications Corporation (In re Maxwell Communications Corp). 170 B.R. 800, *817 e nota de rodapé 22. Nova York, 10 de agosto de 1994 (tradução nossa).
} 
casos, os credores não podem determinar precisamente ex ante o país de origem da entidade ou qual lei regerá a distribuição de ativos.

Sendo assim, alguns comentaristas argumentam que um regime universal reduziria o já baixo nível de previsibilidade que existe em casos de insolvências transfronteiriças, e que "[a]s supostas vantagens do universalismo são, na verdade, inalcançáveis", ${ }^{22}$

A discussão anterior explica porque os Estados são relutantes em abraçar completamente a abordagem universalista para resolver os casos de insolvência transfronteiriça. A renúncia de sua soberania é sua principal preocupação e as nações hesitam em se comprometer com o reconhecimento de decisões estrangeiras que aplicam o Direito estrangeiro. Destarte, em que pese o amplo suporte da literatura acadêmica, até o momento, nenhum Estado adotou um verdadeiro modelo universal. Como afirmado por alguns observadores, "mesmo à medida que o mundo cresce mais integrado economicamente $[\ldots]$ continuarão a existir questões sociais, econômicas e políticas em relação às quais as fronteiras e a política local importam".23

A globalização tende a homogeneizar preferências, mas variações locais permanecem.

\subsection{Territorialismo}

A territorialidade clássica - ou territorialismo puro - baseia-se em noções territoriais de soberania, comuns nos estudos do século XIX. Em processos territoriais clássicos, as partes interessadas têm completa autoridade sobre todos os ativos inseridos em determinada jurisdição, mas não podem controlar os que estão fora dela. Em virtude do que o professor John Pottow denominou "orgulho", ${ }^{24}$ os países geralmente possuem um substancial interesse nos bens localizados dentro de seus limites territoriais e não acatam as decisões proferidas fora do seu território.

\footnotetext{
${ }^{22}$ LOPUCKI, Lynn. Cooperation in International Bankruptcy: A post-universalist approach. Cornell Law Review, v. 84, p. 725, 1999 (tradução nossa).

${ }^{23}$ TUNG, op. cit., p. 583.

${ }^{24}$ POTTOW, John. Greed and pride in international bankruptcy: The problems of and proposed solutions to local interests. Michigan Law Review, v. 104, p. 1901, 2006 (tradução nossa).
} 
O territorialismo moderno assemelha-se ao territorialismo clássico apenas em alguns aspectos, já que é bastante mitigado. Ele ainda está muito imbuído da soberania nacional, mas também acolhe a cooperação em processos de insolvência e a harmonização das regras de escolha da lei aplicável. Um processo de insolvência deve ser utilizado somente para administrar os ativos domésticos de um devedor multinacional, nos termos da lei interna e em benefício dos credores nacionais. ${ }^{25}$ Desse modo, se um processo de insolvência envolve um grupo corporativo, apenas os credores da filial local podem participar. Essa regra é baseada na ideia de que os reclamantes locais não receberão sua parcela justa dos ativos em uma insolvência estrangeira e que, consequentemente, um tribunal local deve provê-los e distribuir os ativos dentro de sua própria jurisdição: “[n]inguém na história recente havia seriamente contestado os princípios subjacentes ao universalismo, até o que o professor Lynn LoPucki o fez, em seu artigo de março de 1999, publicado na Cornell Law Review". ${ }^{26}$

Em seu trabalho, LoPucki examina diferentes abordagens concorrentes para resolver os problemas que surgem em casos de insolvência transfronteiriça e conclui que o territorialismo é a mais adequada para tanto: bens localizados em diferentes países devem ser administrados em causas domésticas, na jurisdição em que estão situados. ${ }^{27}$

Seu primeiro argumento em favor do territorialismo - e o ponto mais audacioso de sua teoria - é que ele oferece uma maior previsibilidade ex ante para os credores "que só precisariam conhecer os países onde estão localizados os ativos de seus devedores e as prioridades distributivas desses países para prever seu tratamento na falência". ${ }^{28}$

LoPucki baseia seu argumento na alegação de que, por não haver uma construção prática da regra para definição do país de origem do devedor, o universalismo não é capaz de oferecer uma adequada previsibilidade ex ante. ${ }^{29}$ Essa visão é compartilhada por outros acadêmicos, ${ }^{30}$ que têm afirmado que o territorialismo promove a previsibilidade "porque a identidade do tribunal que decidirá a disposição de um bem em particular e a lei que o tribunal aplicará na sua

\footnotetext{
${ }^{25}$ LOPUCKI, Lynn. Cooperation in International Bankruptcy: A post-universalist approach. Cornell Law Review, v. 84, p. 742-743, 1999.

${ }^{26}$ PERKINS, Lisa. A defense of pure universalism in cross-border corporate insolvencies. New York University Journal of International Law \& Politics, v. 32, p. 813, 2000 (tradução nossa).

${ }^{27}$ LOPUCKI, op. cit., p. 742.

${ }^{28}$ LOPUCKI, op. cit., p. 720.

${ }^{29}$ LOPUCKI, op. cit., p. 713-718.

${ }^{30}$ ADAMS; FINCKE, op. cit., p. 48. Ver também WESTBROOK, Jay. Universal priorities. Texas International Law Journal, v. 33, n. 1, p. 48, 1998.
} 
decisão, são ambas determinadas pelo conhecimento de uma simples informação: a localização desse bem". 31

Essa é a expectativa dos credores ao negociar linhas de crédito.

O segundo argumento apresentado por LoPucki em favor do territorialismo é que, embora os devedores possam facilmente transferir seus bens de um país para o outro, tais transferências são "geralmente limitadas a uma pequena porção dos ativos dos devedor, ocorrem de maneira gradual e são altamente visíveis". ${ }^{32}$ LoPucki afirma que os efeitos das transferências em vésperas de falência também são limitados: "[o]s prejudicados pela transferência podem apresentar reclamações no país para o qual ela foi realizada e atingir os bens indiretamente". ${ }^{33}$ Ele acrescenta que os Estados geralmente têm interesse na "repatriação de bens em evasão" 34 , o que pode ter um efeito devastador sobre a posição de alguns credores. O jurista conclui, portanto, que a questão da retirada estratégica de ativos por devedores insolventes é bastante insignificante. ${ }^{35}$ Essa visão é compartilhada por Adams e Fincke, que argumentam:

Credores cujos interesses seriam materialmente afetados por tal transferência, podem antecipar uma transferência e negociar uma cláusula domesticamente executável em qualquer contrato de empréstimo que impeça ou dificulte uma transferência. ${ }^{36}$

Finalmente, a terceira alegada vantagem do territorialismo é que os custos do processo são menores, uma vez que cada tribunal interno está lidando apenas com os bens localizados em sua própria jurisdição. As reclamações dos credores são contidas em um fórum local, reduzindo assim os custos totais, tanto privados como públicos:

A redução nos custos privados resulta de credores não mais precisarem fazer valer seus créditos em um país estrangeiro. A redução nos custos públicos ocorre a partir de recursos judiciais que são poupados quando os juízos monocráticos têm que

\footnotetext{
${ }^{31}$ KIPNIS, Alexander. Beyond UNCITRAL: Alternatives to universality in transnational insolvency. Denver Journal of International Law \& Policy, v. 36, n. 2, p. 168, 2007 (tradução nossa).

${ }^{32}$ LOPUCKI, Lynn. Universalism unravels. American Bankruptcy Law Journal, v. 79, p.160, 2005 (tradução nossa). Ver também, do mesmo autor, Cooperation in international bankruptcy: A post-universalist approach. Cornell Law Review, v. 84, p. 758, 1999.

${ }^{33}$ LOPUCKI, 2005, op. cit., p. 161 (tradução nossa). Ver também WESTBROOK, Jay. Multinational enterprises in general default: Chapter 15, The ALI principles, and the EU insolvency regulation. American Bankruptcy Law Journal, v. 76, p.18, 2002.

${ }^{34}$ LOPUCKI, 1999, op. cit., p. 758 (tradução nossa).

${ }^{35}$ Ibid., p. 758. Ver também LOPUCKI, Lynn; WARREN, Elizabeth. Secured credit: A systems approach. Nova Iorque: Aspen Law \& Business, 1998. p.300-301.

${ }^{36}$ ADAMS; FINCKE, op. cit., p. 58. Ver também LOPUCKI, 2005, op. cit., p.160-61.
} 
realizar menos audiências de instrução, lidar com menos partes e podem evitar a trabalhosa tarefa de analisar o direito estrangeiro. ${ }^{37}$

Sendo assim, os processos de insolvência em um sistema territorial reduzem "bastante o número de partes, processos contenciosos e audiências de instrução necessárias para resolver os direitos das partes". ${ }^{38}$ Ademais, a situação dos credores também melhora, pois eles podem "litigar em um foro mais próximo e mais conveniente do que aquele que seria estabelecido em um sistema universalista". 39

Para concluir, os defensores do territorialismo têm preconizado que ele "fornece a mais sólida base para a cooperação internacional em matéria de falência multinacional". ${ }^{40}$ Entretanto, esse modelo não é isento de falhas, o que poderia explicar o amplo apoio que o universalismo tem recebido na produção acadêmica.

Curiosamente, a maioria das críticas à territorialidade geralmente corrobora os argumentos a favor do universalismo. Em primeiro lugar, os opositores do modelo territorial não compartilham a visão de que a territorialidade reduz os custos totais do processo, e argumentam que os custos de insolvência para uma empresa multinacional são multiplicados, uma vez que é necessário instaurar processos locais paralelos ao principal, em cada país onde os bens estejam localizados. ${ }^{41}$ Cada jurisdição instaurará seu próprio feito, com administração separada dos ativos e peticionamento e avaliação separados das reclamações, o que multiplica as custas judiciais e os honorários profissionais.

Em segundo lugar, uma reorganização bem sucedida é mais difícil de ser alcançada em um modelo territorial, pois ele torna a coordenação dos casos mais desafiadora. Devido a vários interesses concorrentes, geralmente é difícil atingir o nível necessário de cooperação judiciária e, em vez disso, os conflitos de competência e entre os tribunais se desenvolvem facilmente.

Em terceiro lugar, quanto à afirmação de que o territorialismo promove a preservação da soberania nacional, seus defensores têm argumentado que "a perda de soberania implica que

\footnotetext{
${ }^{37}$ KIPNIS, op. cit., p. 170.

${ }^{38}$ KIPNIS, op. cit., p. 169.

${ }^{39}$ KIPNIS, op. cit., p. 168.

${ }^{40}$ LOPUCKI, 2005, op. cit., p. 760.

${ }^{41}$ WESTBROOK, Jay. A global solution to multinational default. Michigan Law Review, v. 98, n. 7, p. 2309, 2000 .
} 
o país onde os bens estão localizados deve permitir que os seus valores sejam superados pelos valores da jurisdição principal". ${ }^{42}$

Entretanto, Guzman discorda e afirma que esse argumento ignora o fato de que qualquer abordagem do Direito de Insolvência Transfronteiriça envolverá, de certo modo, a renúncia à soberania de algum Estado:

Em termos simples, a atividade empresarial internacional requer o comprometimento de certas noções de soberania nacional, pois muitos países podem ter interesse no destino dos devedores e de seus credores. ${ }^{43}$

Finalmente, um modelo territorial leva a resultados de distribuição desiguais e imprevisíveis, violando o princípio pari passu e aumentando os custos dos empréstimos, em virtude desse cenário de incerteza. ${ }^{44}$

Parece que o debate teórico sobre as vantagens e as desvantagens das abordagens universal e territorial do Direito da Recuperação e Insolvência Transfronteiriças tem se centrado em argumentos específicos, como a previsibilidade ex ante, os custos totais do processo, o sucesso das reorganizações, o valor dos ativos e a justiça. Na prática, porém, nenhuma das abordagens tem sido adotada pelos países, essencialmente porque o territorialismo é muito caro e o universalismo é politicamente inviável. As duas abordagens são melhor vistas, portanto, como os dois ideais e extremos muito teóricos no espectro regulatório, com várias formas modificadas intermediárias.

O objetivo do presente artigo não é participar desse debate teórico na tentativa de determinar qual é a melhor abordagem, mas sim revelar que ele tem origem nos Estados Unidos e tem se concentrado em abordagens idealistas do Direito da Recuperação e Insolvência Transfronteiriças. Espera-se demonstrar que tal debate não tem sido muito engajado, nem adotado em instrumentos regulatórios, o que leva à conclusão de que o Direito da Recuperação e Insolvência Transfronteiriças precisa de um novo marco teórico.

\footnotetext{
${ }^{42}$ GUZMAN, op. cit., p. 2205.

${ }^{43}$ GUZMAN, op. cit., p. 2206.

${ }^{44}$ UNT, Lore. International relations and international insolvency cooperation: Liberalism, institutionalism, and transnational legal dialogue. Law \& Policy International Business, v. 28, p. 1043, 2007.
} 


\section{O DEBATE NA PRÁTICA: UMA ANÁLISE DO REGULAMENTO EUROPEU DE INSOLVÊNCIA DE 2000 E DA LEI DE INSOLVÊNCIA TRANSFRONTEIRIÇA DE 1997 DA UNCITRAL}

Desde a recente crise econômica e financeira mundial, os processos de insolvência transfronteiriça têm aumentado, reavivando o debate sobre a melhor abordagem para se criar um regime internacional de insolvência eficiente. A crise e seus desdobramentos internacionais mostram que o debate teórico apresentado acima foi largamente descartado e substituído por uma abordagem mais razoável e fundamentada, que tentou alcançar soluções que, embora descritas como mais modestas em seu escopo, também são mais realizáveis nas circunstâncias atuais. De fato, esses avanços "modestos" foram necessários e enfrentaram problemas imediatos.

A presente seção argumenta que a discussão a respeito do universalismo e do territorialismo é mais proeminente no plano acadêmico do que na prática internacional, utilizando o Regulamento Europeu de Insolvência de 2000 e a Lei Modelo de Insolvência Transfronteiriça de 1997 da UNCITRAL ${ }^{45}$ para provar esse ponto. Ambas são iniciativas internacionais que conquistaram amplo apoio, apesar do conflito não resolvido entre universalismo e territorialismo, devido à sua abordagem incremental para a solução de problemas. A Lei Modelo da UNCITRAL é uma iniciativa internacional bem sucedida, baseada num amplo consenso entre os signatários, embora permaneça muito ancorada no universalismo. O Regulamento Europeu é um exemplo de compromisso pragmático, afastando-se do debate teórico e fundamentando a lei de insolvência na realidade prática. Ambos são progressivos e demonstram que os Estados podem desenvolver códigos internacionais para lidar com casos transfronteiriços, mesmo sem abraçar uma abordagem ou outra.

\subsection{A Lei Modelo de Insolvência Transfronteiriça da UNCITRAL}

\footnotetext{
${ }^{45}$ UNITED NATIONS COMMISSION ON INTERNATIONAL TRADE LAW (UNCITRAL). Model Law on cross-border insolvency with guide to enactment and interpretation. Nova Iorque: United Nations Publication, 2014.
} 
A Lei Modelo da UNCITRAL é aqui estudada com o objetivo de analisar seu enquadramento teórico e seu lugar no debate entre universalismo e territorialismo. É uma das primeiras iniciativas do movimento internacional que reformou o campo do Direito da Insolvência Transfronteiriça, seguida, por exemplo, do Projeto de Guia Legislativo sobre regras de insolvência da UNCITRAL (UNICTRAL's best practices Draft Legislative Guide), ${ }^{46}$ o Projeto de Insolvência Transnacional do American Law Institute (ALI's Transnational Insolvency Project) ${ }^{47}$ e do Regulamento Europeu de Insolvência de 2000. De fato, após uma série de iniciativas internacionais fracassadas no campo das insolvências transfronteiriças, a Lei Modelo entrou em vigor em 1997 e conquistou amplo apoio.

Pottow tem sido um dos mais vocais apoiadores da Lei Modelo. Curiosamente, sua análise não se limita a avalia-la contra a divisão teórica entre universalismo e territorialismo, mas a compara com tentativas anteriores de reforma fracassadas, chegando à conclusão de que "a decisão explícita dos redatores da Lei Modelo de não tomar uma posição firme no conturbado debate universalismo-territorialismo é uma das características centrais e distintivas do diploma legal", 48

É interessante notar que a Lei Modelo não resolve o debate teórico entre universalismo e territorialismo, pois os redatores parecem ter se afastado totalmente dessa questão. Como assinala Pottow, "a Lei Modelo e seu Guia de Promulgação sequer usam as palavras 'territorialismo' ou 'universalismo'". ${ }^{49}$ A Lei Modelo não implementou um regime universal completo, mas mistura aspectos do territorialismo com "passos de bebê - em áreas discretas e despretensiosas - em direção ao universalismo". ${ }^{0}$

O sucesso da Lei Modelo também repousa no seu enfoque procedimental. Como os Estados estão geralmente mais dispostos a abrir mão da soberania regulatória em questões procedimentais do que em questões substanciais, os redatores da Lei Modelo astutamente a

\footnotetext{
${ }^{46}$ UNITED NATIONS COMMISSION ON INTERNATIONAL TRADE LAW (UNCITRAL). Draft Legislative guide on insolvency law, 24th Session. Nova Iorque, 23 jul. - 3 ago. 2001.

47 Ver FLETCHER, Ian F.; WESSELS, Bob (Relators). Transnational Insolvency: Global principles for cooperation in international insolvency cases. Report to American Law Institute, [Filadélfia], Mar. 2012

48 POTTOW, John. Procedural incrementalism: A model for international bankruptcy. Virginia Journal of International Law, v. 45, n. 4, p. 959, 2005 (tradução nossa).

${ }^{49}$ Ibid., p. 960 (nota de rodapé 106).

${ }^{50}$ Ibid., p. 992.
} 
desenharam como um instrumento procedimental. Essa é uma das principais razões que explicam a adesão à Lei Modelo por um vasto número de países, pois os Estados:

Empenhados em mostrar [...] boa-fé na cooperação internacional em matéria de
Direito da Insolvência - mas profundamente hesitantes em renunciar completamente
ao [seu] compromisso mais substancial com o universalismo ou o territorialismo -
podem prontamente assinar um acordo internacional como a Lei Modelo que pretende
disciplinar o "mero procedimento". 51

Finalmente, outra razão pela qual a Lei Modelo pode ser considerada bem-sucedida é por sua abordagem incremental, que os redatores decidiram perseguir após iniciativas anteriores de reforma mais ambiciosas terem fracassado. Os ajustes lentos e a adaptação dos Estados signatários são fundamentais. A Lei Modelo, portanto, é um instrumento internacional muito pragmático, que adota uma abordagem indireta para a reforma. Como o "mergulho profundo no universalismo [havia sido] tentado, e fracassado, com esforços internacionais anteriores", 52 os redatores decidiram adotar um caminho de reforma em múltiplas etapas, com a Lei Modelo como o primeiro passo, seguido de reformas subsequentes, permitindo que o universalismo permeasse a prática transnacional, um instrumento internacional de cada vez.

Em suma, a Lei Modelo tem um espírito bastante universalista e é vista como um passo concreto em direção à promoção dos objetivos do universalismo. No entanto, seus redatores foram realistas quanto à recepção de um instrumento puramente universal e, consequentemente, incorporaram a Lei Modelo no pragmatismo, optando por um modelo de incrementalismo procedimental. ${ }^{53}$ Essa abordagem ajudou a assegurar um amplo apoio de vários países, devido à orientação procedimental da Lei Modelo e a sua abordagem branda da reforma, o que também explica sua caracterização como uma mudança modesta.

\subsection{O Regulamento Europeu de Insolvência}

\footnotetext{
${ }^{51}$ Ibid., p. 994.

52 Ibid., p. 998.

${ }^{53} \mathrm{O}$ termo foi cunhado pelo professor John Pottow (ver POTTOW, John. Procedural incrementalism: A model for international bankruptcy. Virginia Journal of International Law, v. 45, n. 4, p. 935-1015, 2005).
} 
O Regulamento Europeu de Insolvência (doravante, REI) entrou em vigor em 2002, após um longo e conflituoso processo que começou na década de $1970 .{ }^{54}$

Logo, o REI foi elaborado durante um período em que a natureza dos casos de insolvência não era a mesma de hoje, antes que a recente crise econômica e financeira mundial causasse estragos nos Estados-membros da União Europeia, introduzisse casos de "megas insolvências" 55 e impulsionasse a expansão da cultura de recuperação.

As disposições do REI foram redigidas de modo a proporcionar clareza e certeza no âmbito do Direito da Insolvência Transfronteiriça em toda a União Europeia. Como resultado, os redatores debruçaram o REI sobre o conceito central do centro de interesses principais do devedor. O Estado-membro onde o devedor tem o seu centro de interesses principais é competente para regulamentar o processo de insolvência principal, que tem efeito universal sobre todos os Estados-membros. A lei do país onde está localizado o centro de interesses principais do devedor aplica-se à administração da totalidade de seu patrimônio, independentemente da localização dos bens. Além disso, tal país é competente não apenas para reger o processo de insolvência, mas também para regulamentar os critérios de distribuição. ${ }^{56}$ Um exame cuidadoso das regras, no entanto, revela que são previstas várias exceções a essa regra geral do centro de interesses principais, permitindo que os Estados-membros legislem sobre questões internas específicas, imbuindo o enfoque universal de alguns aspectos do territorialismo.

O primeiro exemplo de exceção é que o Estado-membro onde o devedor tem um "estabelecimento" tem competência para abrir processos secundários com efeitos territoriais. ${ }^{57}$ Esses processos secundários destinam-se a proteger os credores locais, cujos créditos poderiam ser tratados como não preferenciais nos termos da lei do país que trata do processo principal. Um sistema verdadeiramente universal daria todos os poderes ao administrador judicial no processo principal e tornaria o administrador secundário "um mero subalterno responsável por

\footnotetext{
${ }^{54}$ UNIÃO EUROPEIA. Regulamento (CE) no 1346/2000 do Conselho, de 29 de maio de 2000. Relativo aos processos de insolvência. Jornal Oficial da União Europeia, ${ }^{\circ}$ L 160, [Bruxelas], 30 jun. 2000. p. 1-18.

${ }_{55}$ Termo retirado do texto: FLOOD, John; SKORDAKI, Eleni. Normative bricolage: Informal rule making by accounts and lawyers in mega insolvencies. In: TEUBNER, Gunther (Ed.). Global Law Without a State. Aldershot: Dartmouth Publishing Co Ltd, 1997. p.109 (tradução nossa).

${ }^{56}$ Art. $4^{\circ}$, item 2, do Regulamento (CE) $n^{\circ}$ 1346/2000.

${ }^{57}$ Art. $2^{\circ}$ do Regulamento (CE) $n^{\circ} 1346 / 2000$.
} 
recolher ativos e transferi-los para o processo principal para distribuição de acordo com a lei que rege esse processo. Mas não é isso que o Regulamento faz". ${ }^{58}$

Por conseguinte, o REI se baseia em um modelo do denominado "universalismo mitigado", 59 que consiste em uma abordagem pragmática para resolver questões de insolvência transfronteiriça.

Durante a elaboração da Convenção relativa aos Processos de Insolvência de 23 de novembro de $1995^{60}$ - a antecessora do REI - foi levantada a tradicional divisão universalismo/territorialismo. A resolução que acompanhava a Convenção afirmava que "após o alargamento da Comunidade a partir de 1973, [...] [um segundo projeto de Convenção] previa um processo único que deveria ser reconhecido em todos os outros Estados signatários, não sendo admissíveis processos locais paralelos nesses outros Estados [...]". 61

Parece, portanto, que a instauração de processos secundários e, consequentemente, o conceito de territorialidade, foram rejeitados na Convenção original. Essa Convenção, entretanto, nunca entrou em vigor, pois não foi assinada por todos os Estados-membros. Posteriormente, no REI, o princípio do universalismo foi muito afrouxado. As instituições europeias perceberam que, se quisessem alcançar um consenso entre os Estados-membros, teriam que diminuir o alcance e a ambição do instrumento que iriam redigir. $\mathrm{O}$ fracasso da Convenção foi considerado uma prova de que o seu objetivo era demasiado elevado e as instituições europeias reconheceram os limites que os Estados soberanos dificilmente ultrapassariam nessa fase da integração da Europa. Seu entusiasmo original foi rapidamente substituído por uma visão pragmática da situação e os processos secundários foram incluídos no REI como uma concessão necessária para receber o apoio dos países territorialistas.

Em consequência, embora a literatura acadêmica sustente que o universalismo continua sendo um objetivo a ser alcançado como a solução ideal para as questões de insolvências transfronteiriças, também tem amplamente aceitado que ele é descabido no futuro próximo na

\footnotetext{
${ }^{58}$ MCCORMACK, Gerard. Jurisdictional competition and forum shopping in insolvency proceedings. Cambridge Law Journal, v. 68, n. 1, p.174, mar. 2009 (tradução nossa).

${ }^{59}$ MCCORMACK, Gerard. US exceptionalism and UK localism? Cross-Border insolvency law in comparative perspective. Legal Studies, v. 36, n. 1, p. 193, mar. 2016 (tradução nossa).

${ }^{60}$ UNIÃO EUROPEIA. Convention on insolvency proceedings of 23 November 1995 (CONV/INSOL/X1), apud OMAR, Paul. European Insolvency Law. Aldershot: Ashgate Publishing Ltd, 2004. Appendix 2.

${ }^{61}$ UNIÃ̃O EUROPEIA. Resolução sobre a Convenção relativa aos processos de insolvência de 23 de novembro de 1995. Jornal Oficial da União Europeia, n C 279, [Bruxelas], 1 out. 1999. p. 499.
} 
União Europeia. Desse modo, o universalismo foi abandonado em favor de uma abordagem da "arte do possível", ${ }^{62}$ que busca soluções mais viáveis no momento, embora mais modestas em seu escopo. Como os processos territoriais ainda tramitam no quadro europeu, as reformas atualmente em curso na União Europeia tentam aumentar o nível de cooperação entre os Estados-membros, de sorte que os últimos avanços se deslocaram da divisão teórica entre universalismo e territorialismo para uma abordagem mais realista, centrada na cooperação transfronteiriça.

Os comentaristas vêm demonstrando diversos níveis de apoio às iniciativas europeias. Alguns estudiosos descreveram as últimas reformas como "muito decentes", enquanto outros as têm caracterizado como uma "modesta tentativa [...] de melhorar o status quo" ${ }^{63}$ Contudo, as iniciativas europeias não devem ser criticadas com demasiada veemência e devem ser tomadas pelo seu valor aparente: um empreendimento pragmático inserido em um processo contínuo que não deve ser medido pelo padrão do universalismo, o qual tem sido reconhecido como irrealizável no estágio atual da integração europeia. A análise anterior revelou que, na prática, nenhum dos lados do debate foi adotado em instrumentos regulatórios concretos, que, em vez disso, seguiram uma abordagem pragmática. Vale ressaltar que dois instrumentos diferentes, como o REI e a Lei Modelo, com mandatos e objetivos distintos, adotaram uma estratégia semelhante para a regulamentação da insolvência transfronteiriça. A falta de engajamento com o debate em torno do universalismo e do territorialismo leva à conclusão de que há uma evidente necessidade de repensar a o Direito da Recuperação e Insolvência Transfronteiriça para adequar as considerações teóricas às realidades práticas.

\section{A NECESSIDADE DE UM NOVO MARCO TEÓRICO PARA A REGULAMENTAÇÃO DA RECUPERAÇÃO E DA INSOVÊNCIA TRANSFRONTEIRIÇAS}

\footnotetext{
${ }^{62}$ FLETCHER, Ian. European convention on insolvency proceedings: Choice-of-law provisions. Texas International Law Journal, v. 33, p. 124, 1998 (tradução nossa).

${ }^{63}$ EIDENMULLER, Horst. A new framework for business restructuring in Europe: the EU commission's proposals for a reform of the european insolvency regulation and beyond. Maastricht Journal of European and Comparative Law, v. 20, p. 150, 2013 (tradução nossa).
} 


\subsection{Explicando as circunstâncias por trás do abandono do debate entre universalismo e territorialismo}

O debate sobre a divisão entre universalismo e territorialismo não é novo e dificilmente será resolvido em breve. As nações são resistentes em relação à sua soberania regulatória e as autoridades decisórias são cautelosas. Todavia, diferentes pontos precisam ser levantados em relação ao debate tradicional.

Primeiramente, vale enfatizar as diferenças significativas entre o debate nos Estados Unidos e na União Europeia. Embora ambos os entes partilhem um número crescente de semelhanças no campo do Direito da Insolvência, o debate sobre universalismo/territorialismo não se materializou de forma similar. A discussão teórica parece ser mais proeminente e vocal na literatura americana enquanto o envolvimento da União Europeia tem sido, em geral, mínimo. Isso poderia ser devido à principal diferença que ainda existe entre os sistemas da UE e dos EUA em termos de lei de insolvência: este é um verdadeiro Estado federal, enquanto aquela é uma entidade supranacional sui generis, às vezes qualificada como quasi-federal. ${ }^{64}$ Nos EUA, a lei de falências é produzida a nível federal, ${ }^{65}$ enquanto que, na UE, a lei de insolvência continua a ser competência dos Estados-membros e de seus tribunais domésticos. Consequentemente, a implementação de um regime verdadeiramente universal na União Europeia é uma tarefa difícil, pois significaria a elaboração de uma lei comum a todas as jurisdições. Tal tarefa só pode ser realizada pela entidade, que não tem competência para fazêlo nesse domínio específico. Portanto, o fato de o debate entre universalismo e territorialismo ser historicamente mais proeminente nos EUA em comparação com a UE pode ser explicado por suas diferenças constitucionais.

Em segundo lugar, o presente artigo contesta o ponto levantado por alguns comentaristas ${ }^{66}$ nos últimos anos de que, tanto na UE quanto nos EUA, o debate teórico sobre

\footnotetext{
${ }^{64}$ MUCCIARELLI, Federico. Optimal allocation of law-making power over bankruptcy law in 'federal' and 'quasi-federal' legal systems: is there a case for harmonizing or unifying bankruptcy law in the EU? Law \& Economics Research Paper Series, Working Paper no 11-28, set. 2011.

${ }^{65}$ Art. 1, s. 8, Constitution of the United States of America.

${ }^{66}$ MOHAN, Chandra. Cross-border insolvency problems: Is the UNCITRAL model law the answer? International Insolvency Review, v. 21, n. 3, p. 199, 2012; NUNES, Claudia Ribeiro Pereira; MACHADO, Maria de Alencar. Transnational insolvency in the OGX case international: Territorialist or universalist model? In: FRENKEL David; CHRONOPOULOU, Anna (Eds.). Business, Economics and Mercantile Law: Selected Issues. [Grécia]: Athens Institute for Education and Research, 2016. p.55-64; SEXTON, Anthony. Current problems and trends in the administration of transnational insolvencies involving enterprise groups: the mixed record of protocols, the
} 
universalismo e territorialismo permanece em curso. A discussão teve origem nos anos 90, nos EUA, e a maioria das contribuições sobre o tema foi publicada naquela década. Na verdade, os principais artigos de Westbrook e LoPucki foram publicados entre 1990 e 2003. Outros comentaristas americanos, como K. Anderson, E. Adams e J. Fincke, A. Guzman, E. Janger, J. Pottow e R. Rasmussen, por exemplo, mantiveram o debate vivo mais um pouco, com publicações até 2006. Entretanto, desde meados dos anos 2000, o debate teórico nos EUA parece ter estagnado, já que nenhuma nova grande publicação foi editada.

Na União Europeia, em nível acadêmico, a discussão em torno do universalismo e do territorialismo tem sido muito mais tranquila desde o início, como é evidenciado pela escassez de contribuições acadêmicas acerca do tema. Os principais acadêmicos europeus que escreveram sobre o assunto são McCormack, Omar e Wessels. ${ }^{67}$

Muitos artigos de periódicos e de conferências têm feito menção à tradicional divisão entre universalismo e territorialismo, mas geralmente ela não é o escrutínio central dessas análises. A divisão apenas fornece a moldura dentro da qual outro tema é estudado e discutido. Além disso, publicações europeias recentes sobre o tema do Direito Europeu ou Internacional da Insolvência parecem ter pulado completamente a discussão. Assim, argumenta-se que o debate teórico sobre universalismo e territorialismo em casos de insolvência transfronteiriça não está mais em curso. Pelo contrário, ele parou, especialmente na UE.

Em terceiro lugar, considerando esse desinteresse dos acadêmicos europeus, não é de se surpreender que nenhuma menção ao debate teórico seja feita pelas instituições europeias em

UNCITRAL model insolvency law, and the EU insolvency regulation. Chicago Journal of International Law, v. 12, n. 2, p. 811, 1 jan. 2012.

${ }^{67}$ (1) MCCORMACK, Gerard. Universalism in insolvency proceedings and the common law. Oxford Journal of Legal Studies, v. 32, n. 2, p. 325-347, 2012; Jurisdictional competition and forum shopping in insolvency proceedings. Cambridge Law Journal, v. 68, n. 1, p.169-197, mar. 2009; Reforming the european insolvency regulation: A legal and policy perspective. Journal of Private International Law, v.10, n. 1, p. 41-67, 2014; (2) OMAR, Paul. The landscape of international insolvency law. International Insolvency Review, v. 11, p. 173-200, 2002; ___ . New initiatives on cross-border insolvency in Europe. Insolvency Lawyer, v. 5, p. 211, $2000 ; \ldots$. The new european legal order in insolvency: Fundamental legal bases and harmonisation initiatives. Insolvency Intelligence, v. 17, n. 2, p.17, 2004; ___. The european insolvency regulation 2000: A paradigm of international insolvency cooperation. Bond Law Review, v. 15, n. 1, p. 214-243, 2003; e (3) WESSELS, Bob. Contracting out of secondary insolvency proceedings: The main liquidator's undertaking in the meaning of Article 18 in the proposal to amend the EU insolvency regulation. Brooklyn Journal of Corporate Finance and Commercial Law, v. 9, n. 1, p. 63-110, 2015; . Amending the EU insolvency regulation: Shaken or stirred? In: PARRY, Rebecca (Ed.). The Reform of International Insolvency Rules at European and National Level. Nottingham: INSOL Europe, 2011. p. 125-135; in Europe. Juridica International XII, p. 116-124, 2007. 
seus esforços para reformar o panorama da insolvência na Europa. Um exame da Recomendação da Comissão Europeia de 12 de março de 2014 sobre uma nova abordagem em matéria de falência e de insolvência das empresas, ${ }^{68}$ do Regulamento Europeu de Insolvência Reformulado de 2015, ${ }^{69}$ da Proposta de Diretiva de Insolvência de $2016,{ }^{70}$ bem como dos documentos preparatórios elaborados pelas instituições europeias, revela que elas não se envolveram muito no debate. Uma das únicas menções à discussão feitas pela Comissão Europeia é o reconhecimento da "dificuldade em encontrar um equilíbrio entre a universalidade da insolvência do devedor e a territorialidade dos processos" no edital de sua Consulta sobre o Futuro da Lei de Insolvência Europeia (Consultation on the Future of European Insolvency Law). ${ }^{71}$

Ademais, argumenta-se que, mesmo quando as instituições europeias enfrentam os conceitos de universalismo e territorialismo, o fazem não de forma puramente teórica, mas de um ponto de vista pragmático e realista. No Sumário Executivo que acompanha a revisão do REI, a Comissão Europeia propôs duas opções de políticas:

\footnotetext{
Opção A: atualizar o Regulamento existente, mantendo o equilíbrio atual entre credores e devedores e entre universalidade e territorialidade; e

Opção B: alterar as premissas básicas do Regulamento e exigir alguma aproximação ou convergência das legislações e processos nacionais de insolvência.

A Opção A [...] mantém o equilíbrio atual entre devedor e credor e entre universalidade e territorialidade. No entanto, não enfrentaria uma das principais causas dos problemas - ineficiências e diferenças nas legislações nacionais de insolvência.

A Opção B é potencialmente mais eficaz do que a Opção A para alcançar os objetivos e proporcionar benefícios econômicos e sociais para o mercado único. Ela aumentaria a eficácia e a eficiência dos processos de insolvência na UE como um todo; criaria elementos de um sistema totalmente universal, semelhante a algumas das características da regulamentação da insolvência que rege os 50 Estados dos EUA, a Lei de Insolvência dos EUA.

Contudo, a Opção B teria um impacto mais significativo nos sistemas nacionais [...] [o que] impediria [sua] implementação imediata. Entrementes, os problemas atuais persistiriam e poderiam até piorar.
}

\footnotetext{
${ }^{68}$ UNIÃO EUROPEIA. Recomendação da Comissão de 12 de março de 2014. Sobre uma nova abordagem em matéria de falência e de insolvência das empresas. Jornal Oficial da União Europeia, no L 74, [Bruxelas], 14 mar. 2014. p. 65-70.

${ }^{69}$ UNIÃO EUROPEIA. Regulamento (UE) no 2015/848 do Parlamento Europeu e do Conselho, de 20 de maio de 2015. Relativo aos processos de insolvência. Jornal Oficial da União Europeia, nº L 14, [Bruxelas], 15 jun. 2015. p. 19.

${ }^{70}$ UNIÃO EUROPEIA. Proposta de Diretiva do Parlamento Europeu e do Conselho relativa aos quadros jurídicos em matéria de reestruturação preventiva, à concessão de uma segunda oportunidade e às medidas destinadas a aumentar a eficiência dos processos de reestruturação, insolvência e quitação, e que altera a Diretiva 2012/30/EU. COM (2016)0723 final.

${ }^{71}$ EUROPEAN COMISSION. Consultation on the future of european insolvency Law. [S.1.], 30 mar. $2012-21$ jun. 2012 (tradução nossa).
} 
Portanto, enquanto há evidências que sustentam a Opção B, a Opção A parece ser uma opção mais proporcional na presente fase. Sendo assim, a opção preferida para a revisão do Regulamento de Insolvência é a Opção A. ${ }^{72}$

Fica claro nesse trecho que a Comissão tem uma visão realista da situação política atual da União Europeia. Isso explica porque as iniciativas europeias no campo do Direito da Recuperação e Insolvência Transfronteiriças não abraçaram plenamente uma das duas pontas do espectro teórico. ${ }^{73}$ As instituições europeias há muito compreenderam a necessidade de ir além das considerações puramente teóricas e focar em soluções realistas para questões práticas. A aceitação sensata de que essas teorias não pertencem ao reino da prática e não espelham os atuais acontecimentos europeus ${ }^{74}$ explica a diminuição do escopo dos instrumentos de reforma e a adoção de uma abordagem incremental pelas instituições europeias. Elas consideram que o mais importante, em última análise, é encorajar a cooperação entre os Estados-membros e os tribunais nacionais, urgentemente necessária em casos de insolvências transfronteiriças, e promover melhores práticas. O debate teórico que surgiu nos EUA é grandioso e idealista, e o foco mundial está agora em incentivar a recuperação e a cooperação. Por conseguinte, argumenta-se que o limitado envolvimento das instituições europeias com o modelo teórico, tanto nos vários documentos preparatórios como no REI, em sua versão reformulada e na última Proposta de Diretiva de Insolvência, não diminui a qualidade regulatória desses instrumentos.

Em quarto lugar, utilizada como uma ferramenta para avaliar a importância do papel das instituições europeias no panorama regulamentar da UE e a sua posição em relação às discussões teóricas acadêmicas, a análise do engajamento com o debate tradicional revela que a influência da academia nos órgãos europeus de decisão política (em particular a Comissão), tem sido bastante fraca nesse ponto em particular. As instituições europeias valorizam os pontos de vista dos profissionais do Direito e dos acadêmicos, mas parecem fazê-lo em contextos específicos e limitados, como conferências organizadas pela UE, consultas ou outros estudos financiados. ${ }^{75}$ Todavia, a Comissão Europeia parece menos interessada em debates puramente

\footnotetext{
${ }^{72}$ EUROPEAN COMISSION. Commission staff working document impact assessment accompanying the document revision of regulation (EC) 1346/2000 on insolvency proceedings. SWD (2012) 416 final, p.8, 12-13. [Bruxelas], 2012 (tradução nossa).

${ }_{73}$ BUXBAUM, Hannah. Rethinking international insolvency: The neglected role of choice-of-law rules and theory. Stanford Journal of International Law, v. 36, n. 23, p. 24, 2000.

${ }^{74}$ O Considerando 22 do Regulamento (UE) n ${ }^{\circ}$ 2015/848 do Parlamento Europeu e do Conselho, de 20 de maio de 2015, afirma que "[o] presente regulamento reconhece que não é praticável criar um processo de insolvência de alcance universal na União, tendo em conta a grande diversidade das leis substantivas".

${ }^{75}$ Ver, por exemplo, CONVERGENCE OF INSOLVENCY FRAMEWORKS WITHIN THE EUROPEAN UNION - THE WAY FORWARD (Conference). Bruxelas, 12 jul. 2016; EUROPEAN COMISSION. Consultation on the future of european insolvency law. [S.1.], 30 mar. 2012-21 jun. 2012; EUROPEAN COMMISSION.
} 
teóricos - como a divisão entre universalismo e territorialismo, que não propõe soluções concretas para problemas práticos -, e mais centrada na resolução de questões específicas decorrentes da prática. Isso mais uma vez ilustra a abordagem pragmática adotada pela UE no campo da recuperação e da insolvência transfronteiriças.

Por fim, as instituições da União Europeia e o seu funcionamento têm sido frequentemente condenados por estarem desligados da realidade e serem complexos demais: "um dos desafios mais reconhecidos na comunicação reside na complexidade da informação fornecida pelas instituições da UE". ${ }^{76}$ Afastar-se do debate teórico sobre o universalismo e o territorialismo remedeia essas críticas, pois torna os debates europeus menos abstratos, mais concretos e, portanto, mais acessíveis.

\subsection{A União Europeia precisa de uma teoria própria}

O tradicional debate teórico teve origem nos EUA, onde acadêmicos como Westbrook, LoPucki, Rasmussen, Janger, Anderson, Adam e Fincke debateram durante anos abordagens idealistas do Direito da Recuperação e Insolvência Transfronteiriças. Entretanto, parece que há mais discussão em nível acadêmico do que na prática internacional, como demonstra a falta de engajamento com o debate de grandes iniciativas internacionais, a exemplo da Lei Modelo e do REI, que optaram por uma estratégia regulatória pragmática. Além disso, ela não reflete o contexto mais amplo de governança e regulamentação europeias dentro do qual a lei europeia de recuperação e insolvência é interpretada. Também não aborda as dificuldades de harmonizar a legislação nacional dos Estados-membros em uma UE politicamente conflituosa.

Destarte, o presente artigo conclui que o debate teórico em torno da divisão entre universalismo/territorialismo não está em curso. É, antes, um debate cansado, que não trata, em primeiro lugar, das questões contextuais europeias e, em segundo lugar, das verdadeiras questões atuais dos casos de insolvência transfronteiriça, ou seja: a falta de cooperação eficiente

Consultation on an effective insolvency framework within the EU. Bruxelas, 23 mar. 2016-14 jun. 2016; McCORMACK, Gerard; KEAY, Andrew; BROWN, Sarah; DAHLGREEN, Judith. Study on a new approach to business failure and insolvency: Comparative legal analysis of Member States' relevant provisions and practices, Tender $n^{\circ}$ JUST/2014/JCOO/PR/CIVI/0075. Luxemburgo: Office of the European Union, 2016.

76 STROEKER, Natasha; VAN DER GRAAF, Amber; BUISKOOL, Bert-Jan. Communicating 'Europe' to its citizens: State of affairs and prospects. European Parliament, Directorate-General for Internal Policies, Policy Department B: structural and cohesion policy. Nov. 2014. p.73 (tradução nossa). 
entre tribunais nacionais e profissionais de insolvência; a falta de foco em processos de recuperação em algumas jurisdições; e a falta de mecanismos que lidem de maneira eficiente com grupos de empresas e processos de pré-insolvência. Mais importante, além do fracasso na resolução dessas questões, o presente artigo argumenta que o debate tradicional não é essencial na atual fase para resolver essas questões contemporâneas de casos de insolvência transfronteiriça: "o debate sobre as teorias da insolvência transfronteiriça reflete essencialmente questões que foram levantadas no passado". ${ }^{77}$

O ponto levantado nesse artigo não é que o debate nunca deveria ter começado, mas sim que deveria ter sido abandonado quando se percebeu que as circunstâncias impediam a implementação na prática de um dos modelos propostos. Mais propriamente, o argumento aqui é que o debate deveria ter mudado. O presente artigo identifica o progressivo desengajamento com o debate tradicional como um convite e uma oportunidade para reexaminar a discussão e desenhar um novo marco teórico para substituí-la. É hora de a União Europeia abandonar um debate antigo, predominantemente americano, e desenhar sua própria teoria, adaptada para tratar de suas próprias questões e necessidades particulares.

\section{CONCLUSÃO}

O presente artigo demonstrou que as teorias atuais que informam o Direito Europeu de Insolvência e Reestruturação estão desatualizadas e necessitam de substituição. Embora esteja fora do escopo desse trabalho introduzir uma nova teoria para o Direito da Recuperação e Insolvência Transfronteiriças, a conclusão a que se chegou é que a energia e o entusiasmo devem agora ser dedicados à concepção de um novo marco teórico. Chegou a hora de abordar questões concretas que a União Europeia enfrenta atualmente, a fim de sugerir teorias que correspondam às realidades atuais da legislação de insolvência na UE.

\footnotetext{
${ }^{77}$ MASOUD Benhajj. Theoretical aspects of the cross-border insolvency landscape: issues and perspectives for sub-saharan Africa. Submission for the III Prize in International Insolvency Studies, 2010. p.11 (tradução nossa).
} 


\section{REFERÊNCIAS}

ADAMS, Edward; FINCKE, Jason. Coordinating cross-border bankruptcy: How territorialism saves universalism. Columbia Journal of European Law, v. 15, n. 1, p. 43-88, 008-2009.

BALZ, Manfred. The European Union Convention on insolvency proceedings. American Bankruptcy Law Journal, v. 70, p. 486, 1996.

BOSHKOFF, Douglass. Some gloomy thoughts concerning cross-border insolvencies. Washington University Law Review, v. 72, n. 3, p. 931-941, 1994. Disponível em: $<$ https://openscholarship.wustl.edu/cgi/viewcontent.cgi?article=1734\&context=law lawrevie w>. Acesso em: 25 jun. 2020.

BUXBAUM, Hannah. Rethinking international insolvency: The neglected role of choice-oflaw rules and theory. Stanford Journal of International Law, v. 36, n. 23, p. 23-71, 2000. Disponível em: <https://papers.ssrn.com/sol3/papers.cfm?abstract_id=626461>. Acesso em: 25 jun. 2020.

CONVERGENCE OF INSOLVENCY FRAMEWORKS WITHIN THE EUROPEAN UNION_-THE WAY FORWARD (Conference). Bruxelas, 12 jul. 2016.

EIDENMULLER, Horst. A new framework for business restructuring in Europe: the EU commission's proposals for a reform of the european insolvency regulation and beyond. Maastricht Journal of European and Comparative Law, v. 20, p. 133-150, 2013.

ESTADOS UNIDOS DA AMÉRICA. Constitution of the United States of America, 1787. Disponível em: <https://www.senate.gov/civics/constitution_item/constitution.htm>. Acesso em: 25 jun. 2020.

EUROPEAN COMISSION. Commission staff working document impact assessment accompanying the document revision of regulation (EC) 1346/2000 on insolvency proceedings. SWD(2012) 416 final. [Bruxelas], 2012. Disponível em: <https://eur-lex.europa.eu/legalcontent/EN/TXT/HTML/?uri=CELEX:52012SC0416\&from=EN>. Acesso em: 25 jun. 2020.

Consultation on the future of european insolvency law. [S.1.], 30 mar. 2012-21 jun. 2012. Disponível em: 〈https://www.isda.org/a/wkiDE/eu-euir-isda-response-jun12-final.pdf >. Acesso em: 25 jun. 2020.

EUROPEAN COMMISSION. Consultation on an effective insolvency framework within the EU. Bruxelas, 23 mar. 2016-14 jun. 2016.

FLETCHER, Ian F.; WESSELS, Bob (Relators). Transnational Insolvency: Global principles for cooperation in international insolvency cases. Report to American Law Institute, [Filadélfia], 2012.2 Dar. Disponível <https://iiiglobal.org/sites/default/files/alireportmarch_0.pdf>. Acesso em: 25 jun. 2020. 
FLETCHER, Ian. European convention on insolvency proceedings: Choice-of-law provisions. Texas International Law Journal, v. 33, p. 119-140, 1998.

Insolvency in private international law. Oxford: Clarendon Press, 1999.

FLOOD, John; SKORDAKI, Eleni. Normative bricolage: Informal rule making by accounts and lawyers in mega insolvencies. In: TEUBNER, Gunther (Ed.). Global Law Without a State. Aldershot: Dartmouth Publishing Co Ltd, 1997.

GUZMAN, Andrew. International bankruptcy: In defense of universalism. Michigan Law Review, v. 98, n. 7, p. 2177-2215, 2000. Disponível em: $<$ https://repository.law.umich.edu/cgi/viewcontent.cgi?article=2794\&context=mlr $>$. Acesso em: 25 jun. 2020.

KIPNIS, Alexander. Beyond UNCITRAL: Alternatives to universality in transnational insolvency. Denver Journal of International Law \& Policy, v. 36, n. 2, p. 155-189, 2007. Disponível em: $<$ https://digitalcommons.du.edu/cgi/viewcontent.cgi?article $=1274 \&$ context $=$ djilp $>. \quad$ Acesso em: 25 jun. 2020.

LOPUCKI, Lynn. Cooperation in international bankruptcy: A post-universalist approach. Cornell Law Review, v. 84, p. 696-762, 1999. Disponível em: <https://www.lawschool.cornell.edu/research/cornell-law-review/upload/Lopucki.pdf $>$. Acesso em: 25 jun. 2020.

The case for cooperative territoriality. Michigan Law Review, v. 98, n. 7, p. 2216-2251, $2000 . \quad$ Disponível em: $<$ https://repository.law.umich.edu/cgi/viewcontent.cgi?article $=2795 \&$ context $=\mathrm{mlr}>$. Acesso em: 15 jun. 2020.

. Universalism unravels. American Bankruptcy Law Journal, v. 79, p.143-167, 2005.

LOPUCKI, Lynn; WARREN, Elizabeth. Secured credit: A systems approach. Nova Iorque: Aspen Law \& Business, 1998.

MASOUD, Benhajj. Theoretical aspects of the cross-border insolvency landscape: Issues and perspectives for sub-saharan Africa. Submission for the III Prize in International Insolvency Studies, 2010.2 Disponível em: <https://www.iiiglobal.org/sites/default/files/media/benhajj_shaaban_masoud.pdf $>$. Acesso em: 25 jun. 2020.

MCCORMACK, Gerard. Jurisdictional competition and forum shopping in insolvency proceedings. Cambridge Law Journal, v. 68, n. 1, p.169-197, mar. 2009.

Reforming the european insolvency regulation: A legal and policy perspective. Journal of Private International Law, v.10, n. 1, p. 41-67, 2014.

. Universalism in insolvency proceedings and the common law. Oxford Journal of Legal Studies, v. 32, n. 2, p. 325-347, 2012. 
US exceptionalism and UK localism? Cross-border insolvency law in comparative perspective. Legal Studies, v. 36, n. 1, p. 136-162, mar. 2016.

McCORMACK, Gerard; KEAY, Andrew; BROWN, Sarah; DAHLGREEN, Judith. Study on a new approach to business failure and insolvency: Comparative legal analysis of Member States' relevant provisions and practices. Tender $\mathrm{n}^{\circ}$ JUST/2014/JCOO/PR/CIVI/0075. Luxemburgo: Office of the European Union, 2016. Disponível em: $<$ https://op.europa.eu/en/publication-detail/-/publication/3eb2f832-47f3-11e6-9c6401aa75ed71a1/language-en>. Acesso em: 25 jun. 2020.

MOHAN, Chandra. Cross-border insolvency problems: Is the UNCITRAL model law the answer? International Insolvency Review, v. 21, n. 3, p. 199-223, 2012. Disponível em: $\langle$ https://ink.library.smu.edu.sg/cgi/viewcontent.cgi?article=3097\&context=sol_research>. Acesso em: 25 jun. 2020.

MUCCIARELLI, Federico. Optimal allocation of law-making power over bankruptcy law in 'federal' and 'quasi-federal' legal systems: is there a case for harmonizing or unifying bankruptcy law in the EU? Law \& Economics Research Paper Series, Working Paper $\mathrm{n}^{\circ}$ 11-28, set. 2011. Disponível em: <https://www.academia.edu/896186/Optimal_allocation_of_lawmaking_power_over_bankruptcy_law_in_federal_and_quasi-

federal_legal_systems is there_a_case_for_harmonizing_or_unifying_bankruptcy law_in th e_E.U.>. Acesso em: 25 jun. 2020.

NUNES, Claudia Ribeiro Pereira; MACHADO, Maria de Alencar. Transnational insolvency in the OGX Case International: Territorialist or universalist model? In: FRENKEL David; CHRONOPOULOU, Anna (Eds.). Business, Economics and Mercantile Law: Selected Issues. [Grécia]: Athens Institute for Education and Research, 2016. p. 55-64.

OMAR, Paul. European Insolvency Law. Aldershot: Ashgate Publishing Ltd, 2004. Appendix 2. $218,2000$.

New initiatives on cross-border insolvency in Europe. Insolvency Lawyer, v. 5, p. 211 -

The european insolvency regulation 2000: A paradigm of international insolvency cooperation. Bond Law Review, v. 15, n. 1, p. 214-243, 2003. Disponível em: <http://www.austlii.edu.au/au/journals/BondLRev/2003/10.pdf $>$. Acesso em: 25 jun. 2020.

. The landscape of international insolvency law. International Insolvency Review, v. 11, p. 173-200, 2002. Disponível em: 〈https://www.iiiglobal.org/sites/default/files/landscapeofinternationalinsolvencylaw.pdf $>$. Aceso em: 25 jun. 2020.

.The new european legal order in insolvency: Fundamental legal bases and harmonisation initiatives. Insolvency Intelligence, v. 17, n. 2, p.17-26, 2004. Disponível em: $\langle$ https://www.iiiglobal.org/sites/default/files/neweuropeanlegalorderharmonisation.pdf $>$.

Acesso em: 25 jun. 2020. 
PERKINS, Lisa. A defense of pure universalism in cross-border corporate insolvencies. New York University Journal of International Law \& Politics, v. 32, p. 787-828, 2000.

POTTOW, John. Greed and pride in international bankruptcy: The problems of and proposed solutions to local interests. Michigan Law Review, v. 104, p. 1899-1849, 2006. Disponível em: $\langle$ https://repository.law.umich.edu/cgi/viewcontent.cgi?article $=1617 \&$ context=articles $>$.

Acesso em: 25 jun. 2020.

Procedural incrementalism: A model for international bankruptcy. Virginia Journal of International Law, v. 45, n. 4, p. 935-1015, 2005. Disponível em: <https://repository.law.umich.edu/cgi/viewcontent.cgi?article $=1618 \&$ context=articles $>$. Acesso em: 25 jun. 2020.

RASMUSSEN, Robert. A new approach to transnational insolvencies. Michigan Journal of International Law, v. 19, n. 1, 1997. Disponível em $<$ https://repository.law.umich.edu/cgi/viewcontent.cgi?article $=1436 \&$ context=mjil $>. \quad$ Acesso em; 25 jun. 2020.

SEXTON, Anthony. Current problems and trends in the administration of transnational insolvencies involving enterprise groups: the mixed record of protocols, the UNCITRAL model insolvency law, and the EU insolvency regulation. Chicago Journal of International Law, v. 12, n. 2, p. 811-840, 1 jan. 2012. Disponível em: $\langle$ https://chicagounbound.uchicago.edu/cgi/viewcontent.cgi?article=1630\&context=cjil $>$. Acesso em: 25 jun. 2020.

STROEKER, Natasha; VAN DER GRAAF, Amber; BUISKOOL, Bert-Jan. Communicating 'Europe' to its citizens: State of affairs and prospects. European Parliament, DirectorateGeneral for Internal Policies, Policy Department B: structural and cohesion policy. Nov. 2014. Disponível em: <https://www.europarl.europa.eu/RegData/etudes/STUD/2014/529080/IPOL_STU\%282014 \%29529080_EN.pdf>. Acesso em: 25 jun. 2020.

TUNG, Frederick. Fear of commitment in international bankruptcy. George Washington International Law Review, v. 33, p. 555, 2001.

. Is international bankruptcy possible? Michigan Journal of International Law, v. 23, n. 1, p. 31-102, 2001. Disponível em: $\langle$ https://repository.law.umich.edu/cgi/viewcontent.cgi?article $=1335 \&$ context $=$ mjil $>. \quad$ Acesso em: 25 jun. 2020.

UNIÃO EUROPEIA. Proposta de Diretiva do Parlamento Europeu e do Conselho relativa aos quadros jurídicos em matéria de reestruturação preventiva, à concessão de uma segunda oportunidade e às medidas destinadas a aumentar a eficiência dos processos de reestruturação, insolvência e quitação, e que altera a Diretiva 2012/30/EU. COM (2016) 723 final. Disponível em: $\quad<$ https://eur-lex.europa.eu/legalcontent/PT/TXT/HTML/?uri=CELEX:52016PC0723\&from=EN>. Acesso em: 25 jun. 2020.

. Recomendação da Comissão de 12 de março de 2014. Sobre uma nova abordagem em matéria de falência e de insolvência das empresas. Jornal Oficial da União Europeia, $\mathrm{n}^{\circ}$ 74, 
[Bruxelas], 14 mar. 2014. p. 65-70. Disponível em: < https://eur-lex.europa.eu/legalcontent/PT/TXT/PDF/?uri=CELEX:32014H0135\&from=EN>. Acesso em: 25 jun. 2020.

. Regulamento (CE) no 1346/2000 do Conselho, de 29 de maio de 2000. Relativo aos processos de insolvência. Jornal Oficial da União Europeia, $\mathrm{n}^{\circ}$ L 160, [Bruxelas], 30 jun. 2000. p. 0001-0018. Disponível em: <https://eur-lex.europa.eu/legalcontent/PT/TXT/HTML/?uri=CELEX:32000R1346\&from=EN>. Acesso em: 25 jun. 2020.

. Regulamento (UE) n ${ }^{\circ}$ 2015/848 do Parlamento Europeu e do Conselho, de 20 de maio de 2015. Relativo aos processos de insolvência. Jornal Oficial da União Europeia, ${ }^{\circ}$ L 141, [Bruxelas], 5 jun. 2015. p. 19. Disponível em: < https://eur-lex.europa.eu/legalcontent/PT/TXT/PDF/?uri=CELEX:32015R0848\&from=EN>. Acesso em: 25 jun. 2020.

. Resolução sobre a Convenção relativa aos processos de insolvência de 23 de novembro de 1995. Jornal Oficial da União Europeia, no C 279, [Bruxelas], 1 out. 1999. p. 0499. Disponível em: $\quad$ https://eur-lex.europa.eu/legalcontent/PT/TXT/HTML/?uri=CELEX:51999IP0234(01)\&from=EN>. Acesso em: 25 jun. 2020.

UNITED NATIONS COMMISSION ON INTERNATIONAL TRADE LAW (UNCITRAL). Draft legislative guide on insolvency law, 24th Session. Nova Iorque, 23 de julho - 3 de agosto de 2001. Disponível em: <https://undocs.org/en/A/CN.9/WG.V/WP.54>. Acesso em: 25 jun. 2020 .

. Model law on cross-border insolvency with guide to enactment and interpretation. Nova Iorque: United Nations Publication, 2014. Disponível em: $<$ https://www.uncitral.org/pdf/english/texts/insolven/1997-Model-Law-Insol-2013-GuideEnactment-e.pdf >. Acesso em: 25 jun. 2020.

UNITED STATES BANKRUPTCY COURT, S.D. NEW YORK. Barclays Bank v. Maxwell Communications Corporation (In re Maxwell Communications Corp). 170 B.R. 800. Nova Iorque, 10 de agosto de 1994. Disponível em: <https://www.courtlistener.com/opinion/1551512/in-re-maxwell-communication-corp-plc/>. Acesso em: 25 jun. 2020.

UNT, Lore. International relations and international insolvency cooperation: liberalism, institutionalism, and transnational legal dialogue. Law \& Policy International Business, v. 28, p. 1037-1106, 2007.

WESSELS, Bob. Amending the EU insolvency regulation: Shaken or stirred? In: PARRY, Rebecca (Ed.). The Reform of International Insolvency Rules at European and National Level. Nottingham: INSOL Europe, 2011. p. 125-135.

Contracting out of secondary insolvency proceedings: The main liquidator's undertaking in the meaning of Article 18 in the proposal to amend the EU insolvency regulation. Brooklyn Journal of Corporate Finance and Commercial Law, v. 9, n. 1, p. 63-110, 2015. Disponível em: <https://pdfs.semanticscholar.org/e9f2/e90d5fc7437b9d2ce6336cdffa2cb86c5b2c.pdf $>$. Acesso em: 25 jun. 2020. 
- The changing landscape of cross-border insolvency law in Europe. Juridica International XII, p. 116-124, 2007. Disponível em: $\langle$ https://www.juridicainternational.eu/public/pdf/ji_2007_1_116.pdf $>$. Acesso em: 25 jun. 2020.

WESTBROOK, Jay. A global solution to multinational default. Michigan Law Review, v. 98, n. $7, \quad$ p. 2276-2328, 2000. Disponível em: $\langle$ https://repository.law.umich.edu/cgi/viewcontent.cgi?article $=2797 \&$ context $=\mathrm{mlr}$ >.$\quad$ Acesso em: 25 jun. 2020.

Multinational enterprises in general default: Chapter 15, The ALI principles, and the EU insolvency regulation. American Bankruptcy Law Journal, v. 76, p. 18-21, 2002.

Theory and pragmatism in global insolvencies: Choice of law and choice of forum. American Bankruptcy Law Journal, v. 65, n. 4, p. 457-490, 1991.

Universal participation in transnational bankruptcies. In: CRANSTON, Ross (Ed.). Making Commercial Law: Essays in Honour of Roy Goode. Oxford: Clarendon Press, 1997. p. 419-438.

Universal priorities. Texas International Law Journal, v. 33, n. 1, p. 27-46, 1998.

Data de Submissão: 01/07/2020

Data de Aceite: 05/08/2020 